\title{
Study of Test Anxiety of Freshmen Engineering Boys and Girls Students and their Academic Performance in Science \& Humanities Subjects
}

\author{
P.Bhaskara Reddy, R. Praveen Reddy and M. Kantha Reddy \\ MLR Institute of Technology, Hyd, India MLR Institute of Technology, Hyd, India Hyderabad,India \\ pbhaskarareddy@rediffmail.com; rpredy82@gmail.com; kanthareddy_m@yahoo.com
}

\begin{abstract}
The main aim of this learning was the effect of teaching of self-regulation on test anxiety; college achievement and met cognition in boy students, The Society under study include all boy and girl students of MLRIT. From this society 154 persons were randomly selected as sample that include experiment and control groups and 110 persons were selected for comparative analyzes. Measurement tools was Testanxiety inventory that encountered of reliability and validity. Plan of research was kind of pre-test and post-test with manage group. After of pre-test, experimental groups four week, every week, two sessions and every session, an hour to share in education class of self-regulation. After of end experimental to accomplish post test with two groups. The results of T-test show that there are significant difference between test anxiety in pre-test and post-test. Also we can see differenced levels of test anxiety between this student (22.4=low, 56.8=medium 18.4=high, 18.6 tremendous). Mean scores of test anxiety among students whose parents have academic education is higher than whom their parents don't have academic education that show parents with academic education have more stringent whereas, results of t-test show that there are no significant differences between parents with academic education and no academic education also There are no significant different in mother profession and there are significant difference between boys and girls test anxiety $(t=-4.76, p<0.00)$. With comparison Mean of two groups discover that girls encounter higher test anxiety. Results of meta cognition analyzes show that Mean scores in post-test are higher than pre-test however analyze with t-test method show that there are not significant difference between experimental and control groups in post-test of global reading, problem-solving, support research strategies and total score. results of academic achievement analyzes show that mean scores of courses increase in post-test that show self-regulation is useful in practicable and reading courses. With comparison Mean scores in foreign language books discover that pre-test are almost similar to post-test. Besides analyze with t-test methods show that there are significant difference between experimental and control groups in English, physics, chemistry and mathematics courses $(p<0.05)$ however there are no significant difference in mathematical methods, drawing, English and Hindi courses.
\end{abstract}

Key Words - Learning Skills, Behavior Therapy, Exam Anxiety, Performance in Tests and Mean score 


\section{Introduction}

One of worries and problems of educational system and students is exam problem. Exam, the word that all student are familiar with that and some of them worried by nearing its name of course anxiety have measure and severity and variation undulate. Severity of anxiety is when that exam is near and in exam night increased to its severity. For example terminal exam in may-June and spatially entrance exam. College dropout threaded student society. According to the educational and instructional ministry estimation (in every educational year)of every 110 student dependent to variety bases 45 person were failed and or experienced College dropout[1] According to the studies and empirical dates characterized that almost 60 present of failed students and or persons that showed educational recession in scores. In lower sections and grade were member students that have noticeable achievement however by passing the time and changing sections emerged changes in scores [1] in the way [2] used of The Test Anxiety Inventory for Children and Adolescents (TAICA) test for assessment test anxiety that included scales (problems cognition and inattention, high performance, instrumental anxiety, high physiological arouse, maths humiliation, worry and worry and lie). [3] assessmented two treatment that include regular desensitization and role playing for decreasing test anxiety. The result show that psychological role playing was very effective in anxiety treatment. Another study did by [4] The result showed that various factors effected on test anxiety and also consider that factors that increase student comprehension and resulted that cognition approach with relaxant technique and synthetic interventions decrease test anxiety and increase exam performance and Eye progress Desensitization and reprocessing (EPDR) technique also decrease test anxiety and emotional and worries chosen of this spatially [5] in the way [6] cognitivebehavior therapy (CBT) and reception-based behavior therapy (RBBT) compared for the treatment of test anxiety. Results showed that those receiving $A B B T$ experiencing improvements in performance, whereas those receiving $C B T$ exhibited reduced performance. In addition, there was a suggestion that ABBT might have been more effective at reducing subjectively experienced test anxiety. there are inconsistent with [7] Cognitive and regular desensitization technique in decrease test anxiety were analyzed .results showed that test anxiety was lower in both groups in comparison to control group but there was no significant difference between Cognitive and desensitization technique in lowering test anxiety. Another research was performed to evaluate the lowering methods of anxiety with the aim of training of study skills and cognitive-behavior technique and combination of above mentioned technique and control group, results showed that in ternate groups test anxiety scores were lower than control group [8]. and behavior therapy (concentrate on subjective skills) and cognition effect on test anxiety[9]. [10] tried to unravel the influence of various types of education on test anxiety levels that include a stressful, achievement-orientated education; a reassuring, task-orientated education; and an ambiguous education. It turns out that state anxiety and test anxiety do not increase more rapidly as a function of anxiety disposition under stressful conditions compared with reassuring conditions. As in previous research, stage-fright effects were observed in the sense that repeated measures of state anxiety and test anxiety showed a decline of average anxiety levels.

30 boys and girls participated in a 10 sessions group therapy that include training of muscle relaxation and dealing with stress, findings showed that in experimental groups test anxiety scores were lower than control group also it was higher in females in comparison to males. Group therapy had omnipotent influence in scores related to self-confidence [11] The evaluation of three methods namely cognitive therapy, training of reading skills and control group was done by [12] that showed significant different between control and main groups about test anxiety, The case study of Touki showed that the test anxiety 
P.Bhaskara Reddy, R. Praveen Reddy and M. Kantha Reddy; Study of Test Anxiety of Freshmen Engineering Boys and Girls Students and their Academic Performance in Science \& Humanities Subjects. Transactions on Machine Learning and Artificial Intelligence, Volume 4 No 5 October (2016); pp: 10-27

lowered in cognitive therapy group in comparison to control group. Learning the skills of dealing with emotional in lowering test anxiety and enhancing self-confidence were very important. It is possible to education the above-mentioned skills as life skills to prevent stress [13].

The current study by [14] examined whether material presented in an interactive treatment format was effective in reducing state anxiety and test anxiety and increasing academic performance. A wait-list control group served as the comparison group in this study. The interactive component of the program introduced the ability for participants to test their knowledge of each treatment component, to experience imaginal exposure, and to provide anxiety ratings during exposure sessions. It was predicted that the participants in the treatment group would experience a greater decline in test anxiety than the participants in the wait-list control group.

Also other assessment showed that courses and educational strategy provided by Newcastle MLRIT are better than medicinal and psycho treatment [15] effect educational in interest background and test anxiety assessed on 375 student. the result showed that wasn't significant relation but there was significant relation between practical educational with sexual and interest [16]. Furthermore, In educational low-motive student we faced with students that have high scores in class but by passing the time and changing study grades, their information forget and extinguish. They aren't able to use of their information in variety of positions. Teachers, also aren't able easily able to recognition this kind of students and eliminate their problems. Surfaces activities show that they are active in learning but evaluations don't support [17]. in a research that did by [18] resulted that exam time and reward in exam time can effect on test anxiety. so students divided into three groups. To first group many reward, second group average reward, third group little reward and result showed that the group that received average reward have lowest measure anxiety. Study achievement is need to use of rich learning guidelines and coequal self-esteem and relief of anxiety. Researcher doesn't view higher surface test anxiety the only factor of recession performance. But point to the other factors such as achievement motive decrease, the kind of achievement motive, insufficiency in way study, weak organization, analyze information, etc.

In this way researchers reported students that educated purifying, comprehension and the understanding of cognition aspects have less test anxiety than to groups that watched film about test anxiety and the group that had studied the reports to this syndrome [19]. And also in a research that did by [20] resulted that if students have skull duggery paper in test session their test anxiety decrease significant. In other study metacognition role was considered as a metacognition on test anxiety and study theory. They studied Approaches and Study Skills Inventories for Students (ASSIST) Metacognitions Questionnaire (MCQ), and Test Anxiety Scale (TAS). The result showed that it is the metacognition that effected on test anxiety [21].It seem that learning and study method effect on learning translation. Students that was trained by correct study method educated and used of appropriate study method have high study achievement. On the other way researcher reported that maximum students and even student-MLRIT experimented test anxiety that have negative result [22]. other important factors in making test anxiety, is that students are not familiar with correct study method and curriculum. Most of student study different texts with the same speed and method namely. They study mathematic like Hindi. 
Current research indicates that some gifted students possess better self-regulated learning strategies than their peers, however gifted students may have done very well in college without using good self-regulation strategies because of a combination of their high abilities and/or an unchallenging curriculum. If learning is relatively easy for someone, less effort, organization and other self-regulated activities are expended. Maths conditions or personal issues may prevent students from developing self-regulated learning strategies. For some students who already have some of these strategies, maths or personal issues may prevent them from using them regularly, and thus, they need to be helped and encouraged to do so. Some gifted and talented students display perfectionism and need to learn to strive for excellence (their personal best) rather than perfection. Some talented students with high potential may find it difficult to learn self-regulation when it is not taught, modeled, or rewarded by the adults in their home and family. Even if students interact regularly with adults who demonstrate self-regulation, they may fail to use these skills themselves due to peer pressure or refuse to use the strategies their parents or teachers regularly employ at home or college. Compared with low achieving students, high achievers set more specific learning goals, use a variety of learning strategies, self-monitor more often, and adapt their efforts more systematically. The quality and quantity of self-regulation processes is crucial. We must recognize that one self-regulation strategy will not work for all students, and that the use of only a few strategies will not work optimally for a person on all tasks or occasions. It is important that students learn to use multiple self-regulatory learning skills rather than single strategies. They must also learn that their goals and their choice of self-regulation strategies have to be continually adjusted. Our hope in this module is that we will be able to work with students to help them shift from performance goals to move towards mastery goals, focusing on understanding the material, persisting when they are challenged or their performance fails. This is especially critical for talented students who seldom experience high levels of challenge.

According to [23] self-regulated learning involves the regulation of three general aspects of academic learning.

First, self-regulation of behavior involves the active control of the various resources students have available to them, such as their time, their study environment (e.g., the place in which they study), and their use of others such as peers and faculty members to help them

Second, self-regulation of motivation and affect involves controlling and changing motivational beliefs such as self-efficacy and goal orientation, so that students can adapt to the demands of a course. In addition, students can learn how to control their emotions and affect (such as anxiety) in ways that improve their learning.

Third and finally, self-regulation of cognition involves the control of various cognitive strategies for learning, such as the use of deep processing strategies that result in better learning and performance than students showed previously how does self-regulation develop?

Emotional self-regulation and cognitive self-regulation seem to have the same neural roots; thus, as children grow older and their brains develop, they can increasingly take control of both their thinking and their feelings. Furthermore, if a neural system is repeatedly exercised, it will continue to develop, as with exercising a muscle. Conversely, if children do not systematically engage in self-regulatory behaviors at a young age, the corresponding brain areas may not develop to their full potential [24], [25].

Before of this research, there was not any report of effect training self-regulation on test anxiety and academic achievement and metacognition and in several research were assessed only the test anxiety 
P.Bhaskara Reddy, R. Praveen Reddy and M. Kantha Reddy; Study of Test Anxiety of Freshmen Engineering Boys and Girls Students and their Academic Performance in Science \& Humanities Subjects. Transactions on Machine Learning and Artificial Intelligence, Volume 4 No 5 October (2016); pp: 10-27

relation with variables as fear of success, ways to nurture child, personality pattern, introversionextraversion and the effect of different treatment and also was assessed purpose orientations with learning methods and test anxiety. According to this theory is it possible self-regulation effect on test anxiety and academic achievement and met cognition? Yet to response to this question a research did on the boy student of third level of high college in shahrbabak.

\section{Method Research}

With due attention to this self-regulation suppose as independent variable that researcher supervise in this and also existence of control group is experimental. It means made that tried with making independent variable that include self-regulation, consequences in dependent variable namely assess test anxiety, academic achievement and metacognition in selected students. Design research was of kind pretest and post-test with control group.

The Society under study include all junior boy and girl students of MLRIT branch. From this society 154 persons selected as sample randomly that put in experiment and control groups that.(110 persons were boy students of third level of high college and 54 persons were boy students in guidance college). and 110 persons selected for comparative analyzes.

Design research was of kind pre-test and post-test with control group. For administrating research test anxiety, academic achievement and meatcognition questionnaires administered for two control and experiment group as pre-test. Then all students of experiment group sat encounter in instruction methods training by 8 section, every section, an hour with use of participatory learning and techniques such as lecture, disputation and question and answer and then post-test do. Provided material in sections were:

First section: in the section produced description of effective study and qualification educated that learned to person how of study times have high use.

Second section: the principles of programming, suitable nurture, time of study trained

Third section: it trains about this why we should review subject and also how review them

Fourth section: in this section learning technique one time for always was trained that mastermind by Robinson in year 1996 and its name SQ3R. In the way try to make background in mind before of study, learning process become more and easy

Fifth section: one of the most important learning skills was comprehension and for this need to motive, concentration, prebackground and correct study method. In the background given necessary recommendations specially in background note-writing and memory-tree to students

Sixth section: technique given for increasing mind activity and concentration

Seventh section: fast reading and its obstacles and necessary explanations given to students

Eighth section: necessary explanations given for better performance in exam.

\section{Measurement Tool}

1- test anxiety questionnaire(TAL)include of 25 item that respond according to four division scale( $0=$ never, $1=$ seldom, $2=$ some when, $3=$ often)minimum and maximum score in the test is zero, 75 respectively and also the test encounter suitable reliability and validity. 
Internal consistency: for assessment Internal consistency (TAL) used of Alph Kronbakh. According to provided results Alpha coefficient was for all sample girl and boy, 0.94, 0.95, 0.92 respectively

Retest validity: for assessing validity scale TAL the test repeat afterward from 4 week to 6 week for 91 boys and 90 girls that participate in first stage. Mean and standard deviation of total score girl and boy persons in scale (TAL) in retest stage was $y=34 / 24$ ( $s d=17 / 26), X=32 / 28$ ( $s d=15 / 8), x=2 / 36$ ( $s d=19 / 44)$ respectively. Correlation coefficient between scores of persons in two stage test and retest for all persons include girl and boy were $(r=0 / 77),(r=0 / 88),(r=0 / 67)$ that is satisfactory.

Reliability: for reliability evaluation, TAL this scale with anxiety questionnaire and scale self -steam given to sample students of research to do reliability

Scale 20 item anxiety questionnaire make by factor analysis method and encounter of acceptable and satisfactory psychometric characteristics was made.

Correlation coefficient between all person scores in general anxiety scale or TAL for all sample persons girl and boy are $r=0 / 67, r=0 / 72(p=0 / 001)$ respectively

Also for reliability assessment TAL used of self-steam Kooper Esmite scale that have 58 division and encounter of satisfactory reliability and validity. Correlation coefficient of all persons scores, girl and boy were in scale self-steam with TAL $(r=0 / 57, r=0 / 67, r=0 / 43),(p=0 / 001)$ respectively. Researcher also accounted norms scores of sample persons $(\mathrm{N}=581)$ as percent grade and resulted with comparison person scores girl and boy in scale TAL by one test T. in the result girl scores were more than boys in scale $\operatorname{TAL}(\mathrm{T}=3 / 31, \mathrm{df}=524, \mathrm{p}<0 / 0001)$ at the end, researcher resulted that TAL scale is bonafide for using in psychology researches and recognition test anxiety in children and adolescents in colleges [26].

Meta cognition questionnaire: the first factor analysis showed that a questionnaire measures three factors global reading strategies, problem-solving strategies and support reading strategies. Kronbakh alpha was calculated for each secondary scale and Alpha coefficient was changeable between 89/ to 93/ to shorten the length of the questionnaire, the questions were investigated again and same of the ambiguous questions were deleted because of having low loading, overlapping loading, terminal decreasing traits and being similar to other questions and at the last, thirty items remained for the final prescription were investigated again to remove ambiguity and increase reliability and intelligibility. Afterwards, it performed and conducted on a small group of subjects. By correcting the results of this study, the prepared questionnaire was performed on 443 sixth to twelve-grade students and to analyze data by method like factor analysis and reliability calculate with Kronbakh Alpha were used.

The result of data analysis showed that instead of 60-item questioner the prepare 30 -item questionnaire cam measure 3 determined factors with significant reliability degree. 3 scales of this questionnaire include global reading strategies, problem-solving strategies and support reading strategies. Reliability of the questioner: in accordance with their attempts by compilers that were mentioned before, reliability of the questioner is guaranteed satisfactory.

To investigate reliability kronbakh Alpha coefficient was calculated and the calculated coefficient was reported 89/. Therefore scholars can use the reliability of the mentioned questionnaire without any concern and also scholars can use this questioner for metacognition from/by reading strategies [27]

3-academic achievement questioners: there questioners provided by specialists in measurement and assessment branch and encountered of enough reliability and validity. Readable Courses include 
P.Bhaskara Reddy, R. Praveen Reddy and M. Kantha Reddy; Study of Test Anxiety of Freshmen Engineering Boys and Girls Students and their Academic Performance in Science \& Humanities Subjects. Transactions on Machine Learning and Artificial Intelligence, Volume 4 No 5 October (2016); pp: 10-27

(geography, physics, maths, literature), practicable courses (mathematics, experimental, art, profession) and foreign language course (English, Hindi).

\section{Result}

In the research data analysis with description and inferential statistical method instance mean, standard deviation and test

Test anxiety questionnaire (TAL) include 25 item that responds in basis one scale four division ( $0=$ never, 1=seldom, 2=somewhat, 3=often) minimum and maximum score in the test is zero, 75 respectively.

This test perform in 264 persons, society of boy in shahrbabak city and maximum score test anxiety was 66 and so students were ranking.

\subsection{Test anxiety analyzes:}

Table1: Percent, Median, Mean Students to Severance Degrees Test Anxiety

\begin{tabular}{|l|c|c|c|c|}
\hline \multicolumn{5}{|c|}{ Descriptive Statistical } \\
\hline Degree & Mean & Median & Number & Percent \\
\hline 1 & 15.11 & 17 & 9 & 17.6 \\
\hline 2 & 28.66 & 40 & 27 & 52.9 \\
\hline 3 & 40.90 & 49 & 10 & 19.6 \\
\hline 4 & 56.80 & 55 & 5 & 9.8 \\
\hline Total & $\mathbf{3 1 . 4 3}$ & $\mathbf{3 0}$ & $\mathbf{5 1}$ & $\mathbf{1 1 0}$ \\
\hline
\end{tabular}

The results of table 1 show that percentages of student have test anxiety low, average, much, very much. 17.6, 52.9, 19.6, 9.8 respectively.

Table2: Demographic Table

\begin{tabular}{|c|c|c|c|l|c|c|}
\hline \multirow{2}{*}{ Groups } & \multicolumn{2}{|c|}{$\begin{array}{c}\text { Education of } \\
\text { father }\end{array}$} & \multicolumn{2}{c|}{$\begin{array}{c}\text { Education of } \\
\text { mother }\end{array}$} & \multicolumn{2}{c|}{ Mother 's job } \\
\cline { 2 - 7 } & Acade & No. A & Acade & No A & $\begin{array}{c}\text { House } \\
\text { wife }\end{array}$ & $\begin{array}{c}\text { Employe } \\
\text { e }\end{array}$ \\
\hline Percent & 43.1 & 56.9 & 13.7 & 86.3 & 74.5 & 25.5 \\
\hline
\end{tabular}

Demographic table shows that fathers and mothers of 43 and 13 percentages of students have academic education.

Table3: Descriptive Statistical to Compare Parents Education and Profession

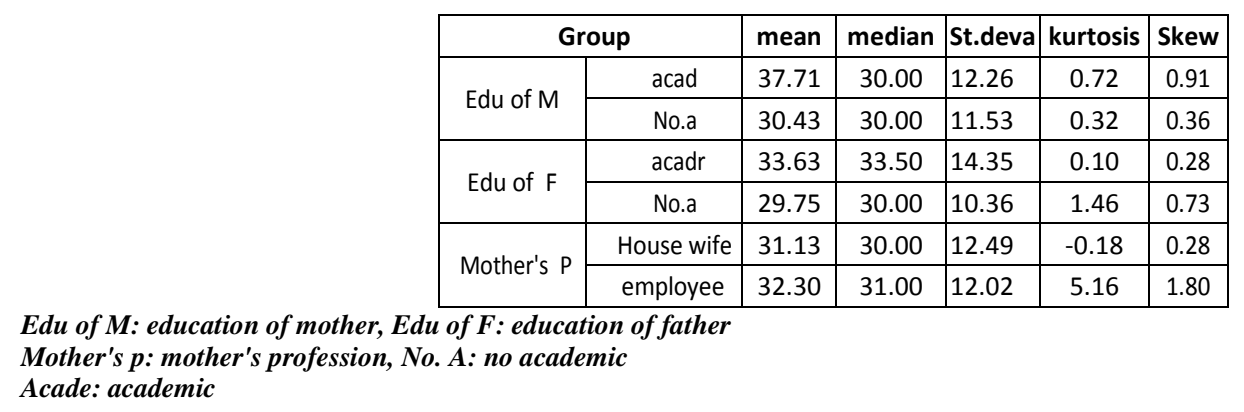


The table shows that the mean score of test anxiety among students whose parents have academic education is higher that show parents with academic education have more stringent. However there is no significant different in mother profession.

Table4: Number, Mean, Std-Deviation in Pre-Test and Post-Test

\begin{tabular}{|c|c|c|c|c|c|c|}
\hline Group & \multicolumn{2}{|c|}{ Number } & \multicolumn{2}{c|}{ Mean } & \multicolumn{2}{c|}{ Std-Deviation } \\
\hline Pre test & 50 & 50 & 31.43 & 32.48 & 12.42 & 12.42 \\
\hline Post test & 50 & 50 & 22.90 & 34.68 & 7 & 14.57 \\
\hline
\end{tabular}

Expe: experimental

As it show in table 4 the mean scores of test anxiety change from 31.43 to 22.90 that showed selfregulation is useful and about control group did not change but improved certainly by approaching tests.

Table5: T-Test for Comparison Pre-Test And Post-Test

\begin{tabular}{|c|c|c|c|c|}
\hline Groups & Mean & T & df & sig \\
\hline Pre-test & 31.43 & 7.79 & 50 & 0.00 \\
\hline Post-test & 22.90 & & & \\
\hline
\end{tabular}

Table 5 show that self-regulation can effect in test anxiety $(t=7.79, p<0.000)$.

Table6: Comparison Test Anxiety In Boy And Girl Students

\begin{tabular}{|c|c|c|c|c|}
\hline Groups & Mean & T & df & sig \\
\hline Boys & 31.43 & -4.66 & 50 & 0.00 \\
\hline Girls & 41.37 & & & \\
\hline
\end{tabular}

Upper table show that there are significant different between boys and girls test anxiety score ( $\mathrm{t}=-4.66$, $p<0.00)$ and we find by comparing mean of two groups that girls encounter higher test anxiety.

Table 7: Comparison of Test Anxiety Based On Father's Education

\begin{tabular}{|c|c|c|c|c|c|}
\hline Groups & F & Sig & T & df & Sig (2-ta) \\
\hline Equ Var & 3.10 & 0.08 & -- & 49 & 0.26 \\
\hline Ass & & & 1.12 & & \\
\hline Equ Var & & & -- & 36.60 & 0.29 \\
\hline Not Ass & & & 1.07 & & \\
\hline
\end{tabular}

Equ. var. ass: equal variance assumed, M: mean

This table shows that there are no significant differences between two groups based on father's education.

Table 8: Comparison of Test Anxiety Based On Mother's Education

\begin{tabular}{|c|c|c|c|c|c|}
\hline \multicolumn{2}{|c|}{ Test anxiety sc. } & \multicolumn{2}{c|}{$\begin{array}{c}\text { Levenne's for } \\
\text { Equ of Var }\end{array}$} & \multicolumn{2}{c|}{ t.test for equ of M } \\
\hline Groups & F & Sig & T & df & Sig (2-ta) \\
\hline Equ Var & 0.77 & 0.38 & -- & 49 & 0.14 \\
\hline Ass & & & 1.47 & & \\
\hline Equ Var & & & -- & 7.06 & 0.27 \\
\hline Not Ass & & & 1.17 & & \\
\hline
\end{tabular}


P.Bhaskara Reddy, R. Praveen Reddy and M. Kantha Reddy; Study of Test Anxiety of Freshmen Engineering Boys and Girls Students and their Academic Performance in Science \& Humanities Subjects. Transactions on Machine Learning and Artificial Intelligence, Volume 4 No 5 October (2016); pp: 10-27

This table shows that there are no significant differences between two groups based on mother's education. Academic achievement analyzes:

Table 9: Descriptive Comparison of Readable Course in Experimental Group

\begin{tabular}{|c|c|c|c|c|r|r|}
\hline \multicolumn{2}{|c|}{$\begin{array}{c}\text { Experimental } \\
\text { group }\end{array}$} & mean & median & St.deva & kurtosis & Skew \\
\hline \multirow{3}{*}{ Hindi } & Pre-test & 16.22 & 17.00 & 2.30 & 0.05 & -0.86 \\
\cline { 2 - 7 } & Post- test & 17.27 & 18.00 & 1.98 & 3.65 & -1.59 \\
\hline \multirow{3}{*}{ Physics } & Pre-test & 18.63 & 19.00 & 1.43 & 1.03 & -1.31 \\
\cline { 2 - 7 } & Post- test & 18.54 & 19.00 & 1.65 & 1.24 & -1.19 \\
\hline \multirow{3}{*}{ Chemistry } & Pre-test & 17.00 & 17.50 & 2.82 & 0.44 & -1.13 \\
\cline { 2 - 7 } & Post-test & 17.95 & 18.50 & 1.88 & 1.28 & -1.23 \\
\hline \multirow{3}{*}{ Drawing } & Pre-test & 17.04 & 17.50 & 2.73 & 1.50 & -1.36 \\
\cline { 2 - 7 } & Post-test & 18.00 & 20.00 & 3.26 & 1.31 & -1.65 \\
\hline \multirow{2}{*}{ Maths } & Pre- test & 18.00 & 18.50 & 2.07 & 1.96 & -1.62 \\
\cline { 2 - 7 } & Post- test & 18.59 & 19.00 & 1.70 & 1.68 & -1.49 \\
\hline
\end{tabular}

As it showed in table9. Mean scores in pre-test are lower than post-test and scores students have noticeable achievement.

Table 10: Descriptive Comparison of Practicable Course in Experimental Group

\begin{tabular}{|c|l|l|l|l|l|l|}
\hline \multicolumn{2}{|c|}{$\begin{array}{c}\text { Experimental } \\
\text { group }\end{array}$} & mean & median & St.deva & kurtosis & Skew \\
\hline & Pre-test & 16.36 & 18.00 & 3.79 & -0.64 & -0.89 \\
\hline
\end{tabular}

\begin{tabular}{|c|c|c|c|c|r|r|}
\hline & Post- test & 17.18 & 18.50 & 2.57 & -0.59 & -0.88 \\
\hline \multirow{3}{*}{ Experimental } & Pre-test & 17.79 & 19.00 & 2.38 & 2.14 & -1.53 \\
\cline { 2 - 7 } & Post- test & 18.31 & 19.00 & 1.91 & 2.71 & -1.85 \\
\hline \multirow{2}{*}{ Drawing } & Pre-test & 19.90 & 20.00 & 0.29 & 8.08 & -3.05 \\
\cline { 2 - 7 } & Post-test & 21.09 & 20.00 & 5.57 & 21.86 & 4.66 \\
\hline \multirow{2}{*}{ Profession } & Pre-test & 19.22 & 20.00 & 1.02 & 0.04 & -1.09 \\
\cline { 2 - 7 } & Post-test & 19.68 & 20.00 & 0.56 & 2.15 & -1.66 \\
\hline
\end{tabular}

The table shows that the mean score of courses increase in post-test that show self-regulation is useful in practicable courses.

Table 11: Descriptive Comparison of Foreign Language Books in Experimental Group

\begin{tabular}{|c|c|c|c|c|r|r|}
\hline \multicolumn{2}{|c|}{$\begin{array}{c}\text { Experimental } \\
\text { group }\end{array}$} & mean & median & St.deva & kurtosis & Skew \\
\hline \multirow{2}{*}{ English } & Pre-test & 18.09 & 19.00 & 2.65 & 0.53 & -1.37 \\
\cline { 2 - 7 } & Post- test & 17.45 & 18.00 & 2.40 & 0.33 & -1.13 \\
\hline \multirow{2}{*}{ Hindi } & Pre-test & 17.61 & 19.00 & 3.03 & 0.93 & -1.31 \\
\cline { 2 - 7 } & Post- test & 18.31 & 19.00 & 2.85 & 5.79 & -2.53 \\
\hline
\end{tabular}

Mean scores in pre-test are almost similar to post-test. 
Table 12: Descriptive Comparison of Readable Courses in Control Group

\begin{tabular}{|c|c|c|c|c|r|r|}
\hline \multicolumn{2}{|c|}{$\begin{array}{c}\text { Control } \\
\text { group }\end{array}$} & mean & median & St.deva & kurtosis & Skew \\
\hline \multirow{2}{*}{ Hindi } & Pre-test & 15.56 & 16.00 & 2.12 & -0.78 & 0.11 \\
\cline { 2 - 7 } & Post- test & 15.59 & 15.00 & 2.01 & -0.46 & 0.62 \\
\hline \multirow{2}{*}{ Physics } & Pre-test & 17.79 & 19.00 & 2.53 & 3.09 & -1.72 \\
\cline { 2 - 7 } & Post- test & 16.72 & 17.50 & 2.67 & -1.07 & -0.48 \\
\hline \multirow{2}{*}{ Chemistry } & Pre-test & 16.86 & 18.00 & 2.91 & 0.17 & -1.13 \\
\cline { 2 - 7 } & Post-test & 15.68 & 16.00 & 2.41 & -0.87 & -0.38 \\
\hline \multirow{2}{*}{ Drawing } & Pre-test & 15.59 & 15.50 & 3.54 & -0.73 & -0.49 \\
\cline { 2 - 7 } & Post-test & 16.13 & 16.00 & 2.35 & -0.57 & -0.27 \\
\hline \multirow{2}{*}{ Maths } & Pre- test & 17.50 & 18.00 & 2.08 & 1.49 & -1.19 \\
\cline { 2 - 7 } & Post- test & 17.09 & 17.00 & 2.02 & -0.76 & -0.40 \\
\hline
\end{tabular}

Mean scores in pre-test are almost similar to post-test and there are no significant different between pretest and post-test

Table 13: Descriptive Comparison of Practicable Courses In Control Group

\begin{tabular}{|c|c|c|c|c|r|r|}
\hline \multicolumn{2}{|c|}{$\begin{array}{c}\text { Control } \\
\text { group }\end{array}$} & mean & median & St.deva & kurtosis & Skew \\
\hline $\begin{array}{c}\text { Mathema } \\
\text { tics }\end{array}$ & Pre-test & 16.36 & 17.00 & 3.31 & 0.19 & -0.95 \\
\cline { 2 - 7 } & Post- test & 15.36 & 15.00 & 2.36 & -0.96 & -0.14 \\
\hline $\begin{array}{c}\text { Experimen } \\
\text { tal }\end{array}$ & Pre-test & 16.70 & 17.00 & 2.11 & 1.26 & -1.05 \\
\cline { 2 - 7 } & Post- test & 16.27 & 16.00 & 2.43 & -0.57 & -0.28 \\
\hline
\end{tabular}

\begin{tabular}{|c|c|c|c|c|r|r|}
\hline \multirow{2}{*}{ Drawing } & Pre-test & 19.90 & 20.00 & 0.29 & 8.08 & -3.05 \\
\cline { 2 - 7 } & Post-test & 19.54 & 20.00 & 0.59 & 0.02 & -0.93 \\
\hline \multirow{2}{*}{ Profession } & Pre-test & 18.00 & 17.00 & 2.11 & 1.26 & -1.05 \\
\cline { 2 - 7 } & Post-test & 17.13 & 17.00 & 1.45 & 0.39 & 0.14 \\
\hline
\end{tabular}

Mean scores in pre-test are almost similar to post-test however mean scores in pre-test are higher than post-test in mathematic and profession because of being more difficult or the increase of capacity

Table 14: Descriptive Comparison of Foreign Language Books In Control Group

\begin{tabular}{|c|c|c|c|c|r|r|}
\hline \multicolumn{2}{|c|}{ Control group } & mean & median & St.deva & kurtosis & Skew \\
\hline \multirow{2}{*}{ Hindi } & Pre-test & 17.27 & 17.50 & 3.22 & 1.97 & -1.45 \\
\cline { 2 - 7 } & Post- test & 16.86 & 17.00 & 2.81 & -0.99 & -0.43 \\
\hline \multirow{3}{*}{ English } & Pre-test & 16.95 & 17.00 & 2.55 & -0.96 & -0.51 \\
\cline { 2 - 7 } & Post- test & 16.40 & 17.00 & 2.80 & -1.12 & -0.40 \\
\hline
\end{tabular}

Mean scores in pre-test are almost similar to post-test.

Table 15: T-Test for Comparison Post-Test in Experimental and Control Groups in Readable Lessons

\begin{tabular}{|c|c|c|c|c|}
\hline \multicolumn{5}{|c|}{ Paired Differences } \\
\hline lessons & mean & t.test & $\boldsymbol{d f}$ & significant \\
\hline Hindi & 1.68 & 2.18 & 21 & 0.040 \\
\hline Physics & 1.81 & 2.44 & 21 & 0.023 \\
\hline Chemistry & 2.27 & 3.27 & 21 & 0.004 \\
\hline Drawing & 1.86 & 1.94 & 21 & 0.065 \\
\hline Maths & 1.50 & 2.69 & 21 & 0.017 \\
\hline
\end{tabular}


P.Bhaskara Reddy, R. Praveen Reddy and M. Kantha Reddy; Study of Test Anxiety of Freshmen Engineering Boys and Girls Students and their Academic Performance in Science \& Humanities Subjects. Transactions on Machine Learning and Artificial Intelligence, Volume 4 No 5 October (2016); pp: 10-27

Upper table show that there are significant different between experimental and control groups in literature, physics, chemistry and maths courses $(p<0.05)$ however there is not significant different in drawing lesson.

Table 16: T-Test for Comparison Post-Test in Experimental and Control Groups in Practicable Courses

\begin{tabular}{|c|c|c|c|c|}
\hline \multicolumn{5}{|c|}{ Paired Differences } \\
\hline lessons & mean & t.test & $d f$ & significant \\
\hline Mathematics & 1.81 & 2.40 & 21 & 0.025 \\
\hline Experimental & 2.04 & 2.84 & 21 & 0.010 \\
\hline Drawing & 1.54 & 1.31 & 21 & 0.202 \\
\hline Profession & 2.54 & 6.97 & 21 & 0.000 \\
\hline
\end{tabular}

Upper table show that there are significant different between experimental and control groups in mathematics, experimental and profession courses $(p<0.05)$. However there are no significant different between experimental and control groups in art course.

Table 17: T-Test for Comparison Post-Test in Experimental and Control Groups In Foriegn Language Books

\begin{tabular}{|c|c|c|c|c|}
\hline \multicolumn{5}{|c|}{ Paired Differences } \\
\hline lessons & mean & t.test & $\boldsymbol{d f}$ & significant \\
\hline English & 1.04 & 1.26 & 21 & 0.21 \\
\hline Hindi & 1.45 & 1.76 & 21 & 0.09 \\
\hline
\end{tabular}

Upper table show that there aren't significant different between experimental and control groups in English and Hindi courses. Meta cognition analyzes:

Table 18: Descriptive Comparison of Met Cognition in Experimental Group

\begin{tabular}{|c|c|c|c|c|r|c|}
\hline \multicolumn{2}{|c|}{$\begin{array}{c}\text { Experimental } \\
\text { group }\end{array}$} & mean & median & St.deva & kurtosis & Skew \\
\hline \multirow{2}{*}{ Glo.rea.s } & Pre-test & 36.36 & 38.50 & 6.53 & 0.50 & -1.16 \\
\cline { 2 - 7 } & Post- test & 39.27 & 37.00 & 7.74 & -1.03 & 0.53 \\
\hline \multirow{3}{*}{ Pro-sol.s } & Pre-test & 29.90 & 32.00 & 6.10 & 4.34 & -1.78 \\
\cline { 2 - 7 } & Post- test & 30.09 & 32.00 & 5.13 & 0.07 & -0.43 \\
\hline \multirow{3}{*}{ Sup.rea.s } & Pre-test & 38.00 & 38.50 & 7.67 & 1.81 & -1.10 \\
\cline { 2 - 7 } & Post-test & 39.45 & 38.50 & 7.19 & -1.13 & 0.07 \\
\hline \multirow{2}{*}{ Total } & Pre-test & 104 & 110 & 183 & 2.47 & -1.49 \\
\cline { 2 - 7 } & Post-test & 106 & 102 & 15.07 & -1.00 & 0.08 \\
\hline
\end{tabular}

Glo. rea. s: global reading strategies pro. sol. s: problem-solving strategies up.rea.s: support research strategies

Mean scores in post-test are higher than pre-test however mean score in pre-test is almost similar to posttest in problem-solving strategies.

Table 19: Descriptive Comparison of Met Cognition in Control Group

\begin{tabular}{|c|c|c|c|c|r|c|}
\hline \multicolumn{2}{|c|}{$\begin{array}{c}\text { Control } \\
\text { group }\end{array}$} & mean & median & St.deva & kurtosis & Skew \\
\hline \multirow{2}{*}{ Glo.rea.s } & Pre-test & 37.27 & 37.50 & 6.34 & -0.62 & 0.16 \\
\cline { 2 - 7 } & Post- test & 38.40 & 39.00 & 5.79 & -0.40 & -0.19 \\
\hline Pro-sol.s & Pre-test & 30.22 & 31.50 & 4.81 & -0.73 & -0.26 \\
\hline
\end{tabular}




\begin{tabular}{|c|c|c|c|c|r|r|}
\hline & Post- test & 30.31 & 30.00 & 3.66 & 0.44 & -0.60 \\
\hline \multirow{3}{*}{ Sup.rea.s } & Pre-test & 41.45 & 42.50 & 5.75 & 0.18 & -0.14 \\
\cline { 2 - 7 } & Post-test & 38.77 & 38.50 & 6.71 & 1.29 & -0.93 \\
\hline \multirow{3}{*}{ Total } & Pre-test & 109.00 & 109.00 & 14.23 & -0.03 & -0.17 \\
\cline { 2 - 7 } & Post-test & 107.50 & 107.50 & 13.58 & -0.39 & -0.33 \\
\hline
\end{tabular}

Mean scores in pre-test are almost similar to post-test in problem-solving strategies however mean scores in pre-test are higher than post-test in support research strategies and total scores.

Table 20: T-Test for Comparison Post-Test in Experimental and Control Groups in Meta Cognition Scales

\begin{tabular}{|c|c|c|c|c|}
\hline \multicolumn{5}{|c|}{ Paired Differences } \\
\hline lessons & mean & t.test & $d f$ & significant \\
\hline Glo.rea.s & 0.86 & 0.40 & 21 & 0.69 \\
\hline Pro.sol.s & -0.22 & -0.14 & 21 & 0.88 \\
\hline
\end{tabular}

\begin{tabular}{|c|c|c|c|c|}
\hline Sup.rea.s & 0.68 & 0.37 & 21 & 0.71 \\
\hline Total & -0.72 & -0.16 & 21 & 0.86 \\
\hline
\end{tabular}

This table show that there are not significant different between experimental and control groups in posttest of met cognition.

\section{Conclusion}

Students that have test anxiety although they learned subjects and concepts and course subjects are not able to provide and express self taught. Society and spatially education, of is fond and worry toward destiny of student in relation with this problem and successful development evolution in society and it expected that should achieve required abilities and skills and it expected that students should achieve required abilities and skills in different cognition, affective, personality aspects to achieve development and ascendancy on the other hand should recognize factors that caused better education and efflorescence of student capacities, and after given them achievement and development .

There is a growing awareness among developmental scientists that the better a child can self-regulate, the better she can rise to the challenge of mastering ever more complex skills and concepts. In the simplest terms, self-regulation can be defined as the ability to stay calmly focused and alert, which often involves - but cannot be reduced to - self-control. The better a child can stay calmly focused and alert, the better he integrates the diverse information coming in from his different senses, assimilates it, and sequences his thoughts and actions. For someone who thinks that self-regulation is really just a matter of a child's getting in control of his negative emotions, there is very little difference between self-regulation and compliance. But, unlike compliance based on punishment, self-regulation nurtures the ability to cope with greater and greater challenges because it involves arousal states, emotions, behavior, and - as the child grows older - thinking skills.

The results of T-test show that there are significant difference between test anxiety in pre-test and posttest. Also we can see differenced levels of test anxiety between this student (17.6=little, 52.9=average, 19.6=high, 9.8 extreme). Mean scores of test anxiety among students whose parents have academic education is higher than whom their parents don't have academic education that show parents with academic education have more stringent whereas, results of t-test show that there are no significant differences between parents with academic education and no academic education also There are no 
P.Bhaskara Reddy, R. Praveen Reddy and M. Kantha Reddy; Study of Test Anxiety of Freshmen Engineering Boys and Girls Students and their Academic Performance in Science \& Humanities Subjects. Transactions on Machine Learning and Artificial Intelligence, Volume 4 No 5 October (2016); pp: 10-27

significant different in mother profession and there are significant difference between boys and girls test anxiety $(t=-4.66, p<0.00)$. With comparison Mean of two groups discover that girls encounter higher test anxiety.

Results of meta cognition analyzes show that Mean scores in post-test are higher than pre-test however analyze with t-test method show that there are not significant difference between experimental and control groups in post-test of global reading, problem-solving, support research strategies and total score.

[28] Comprehend students that have infirmity in information analysis and subject organization experience higher test anxiety during exam. Students that used of low learning level method have problem in information analysis and profound understanding of lesson subjects and result that caused weak academic performance and experience high test anxiety.

Self-regulation is a deep, internal mechanism that enables children as well as adults to engage in mindful, intentional, and thoughtful behaviors. Self-regulation has two sides:

First, it involves the ability to control one's impulses and to stop doing something, if needed-for example; a child can resist his immediate inclination to blurt out the answer when the teacher poses a question to another child.

Second, self-regulation involves the capacity to do something (even if one doesn't want to do it) because it is needed, such as waiting one's turn or raising one's hand. Self-regulated children can delay gratification and suppress their immediate impulses enough to think ahead to the possible consequences of their action or to consider alternative actions that would be more appropriate. While most children know that they are supposed to "use their words" instead of fighting; only children who have acquired a level of selfregulation are actually able to use them. This ability to both inhibit one behavior and engage in a particular behavior on demand is a skill used not just in maths interactions (emotional self-regulation) but in thinking (cognitive self-regulation) as well. For example, to read the word cat when it appears under a picture of a dog, a child must overcome the desire to pay more attention to the picture and instead focus on the word [29]. In fact, research shows that children's self regulation behaviors in the early years predict their college achievement in reading and mathematics better than their IQ scores [30], [31] are almost similar this research, results of academic achievement analyzes show mean scores of courses increase in post-test that show self-regulation is useful in practicable and reading courses. With comparison Mean scores in foreign language books discover that pre-test are almost similar to post-test. Besides analyze with t-test methods show that there are significant difference between experimental and control groups in literature, physics, chemistryand maths courses $(p<0.05)$ however there are no significant difference in drawing, art, english and Hindi courses. Also the results this research is the same as [32] that showed student that used of higher learning method experience more academic achievement than students that used of low learning methods. [33] in every two self study discovered significant and positive relation between academic achievement and profound methods. In research [34] mind review method negatively and supervision in subject perception positively were predictor of academic achievement. And also results of [35] showed that education of cognitive method and met cognitive and cooperative study cause students exhibit better performance in course scores and self-regulation process can effect on decreasing test anxiety students [36]. self-regulation, self-esteem know as negative predictor of test anxiety and external motivations as predictor positive test anxiety [37]. These findings suggest that the Head-to-Toes Task( 
HTT) may be a useful measure of behavioral regulation for Taiwanese precollegeers and provide evidence for the importance of behavioral regulation for academic achievement in Taiwan. Practical implications focus on supporting the development of behavioral regulation in early childhood settings, which can promote early college success [38]. The present study [39] examined the efficacy of a self-regulation intervention with 65 precollege children. Using circle time games, the study examined whether participating in a treatment group significantly improved behavioral self-regulation and early academic outcomes. The findings from this study provide preliminary evidence for the efficacy of the intervention in terms of improving precollegeers' behavioral self-regulation for children low in these skills and improving letter-word identification. Although preliminary, these results have the potential to inform precollege curricula that emphasize behavioral self-regulation as a means of facilitating college readiness. findings suggest that students' self-regulation of learning, self-efficacy beliefs, academic delay gratification, and final course grade are related [40]. Results [41] obtained are mirroring perceived competence of self-regulation and differ from the results concerning metacognitive accuracy. Metacognitive self-regulation persists as an important predictor of college achievement at all developmental levels, and the motivational self-regulation has significant impact on performance in the first and second age group. Finally, children's chronological age, and not whether they experienced one versus two years of precollege, predicted children's vocabulary and self-regulation outcomes. Implications for precollege curricula and instruction are discussed, including the increasing emphasis on literacy learning prior to kindergarten entry and the need to address self-regulation development along with academic learning [42]. Analyses [43] also suggest significant benefits of MLRIT Readiness Project (MRP) for children's preacademic skills, as measured by vocabulary, letter-naming, and math skills. Partial support was found for improvement in children's self-regulation as a hypothesized mediator for children's gains in academic readiness. Implications for programs and policies that support young children's behavioral health and academic success.

Students that encounter in evaluation and exam continuously have low test anxiety and high achievement motive[44] that in this way [45] discovered that students who experience test anxiety in high level when exams them online test anxiety decrease and obvious natural abilities. The current study by [46] influence of genetical evaluation on lowering test anxiety and students academic achievement were analyzed and results showed that they ameliorated the above-mentioned skills but they had no influence on students creativity .Findings [47] provide partial support for the self-regulatory model of test anxiety. Suggesting that additional routes are required to account for the role of parental pressure and teachers' performance-avoidance goals and a re-examination of the relationship between test anxiety and achievement goals. Factor analysis of responses to survey items by a second sample of students refined the initial framework. The final framework comprised three broad domains of perceptions of sources of test anxiety: students' perceptions of the test, their self-perceptions, and their perceptions of the testtaking situation are larger for math than English. Few gender differences emerge, but one prospective analysis reveals that girls who devalue English are more likely to maintain moderate levels of test anxiety across the transition to junior high college. also [50] investigated self-efficacy, gender and trait anxiety as moderators of test anxiety. Results of regression analysis indicated that the model was significant. Selfefficacy contributed $14 \%$ of the variability in test anxiety, whereas trait anxiety moderated $49 \%$ of the variability in test anxiety. Gender was not a significant predictor of test anxiety. Persons with lower selfefficacy had higher test anxiety scores. Also There are Negative correlations between deductive reasoning and standardized test scores [51]. 
P.Bhaskara Reddy, R. Praveen Reddy and M. Kantha Reddy; Study of Test Anxiety of Freshmen Engineering Boys and Girls Students and their Academic Performance in Science \& Humanities Subjects. Transactions on Machine Learning and Artificial Intelligence, Volume 4 No 5 October (2016); pp: 10-27

Results [52] make clear this that test anxiety have significant and positive relation with past exam experience and significant and inverse relation with self-steam. [53] selected number 2482 person in self research and discovered that a) there are weak relation between test anxiety and achievement $b$ )there are positive and significant relation between self-concept and study habits with achievement.

\section{Suggestions}

In the end with regard to results of this study self-regulation education can have a effective role in students test anxiety. So it necessary about this problem more serious. And make courses as the way of study for students to decrease this problem and also achievement and society bright capacity growing.

How help to Self-Regulate in Children?

1. Model self-control and self-regulation in your words and actions when you are frustrated with a classroom situation.

2. Provide structure and predictability. Children with self-regulation problems are internally "unstructured." The more freedom and flexibility they have, the more likely they are to demonstrate uncontrolled behaviors.

3. Anticipate transitions and announce changes in classroom schedules.

4. Reward children with good self-regulation capabilities with freedom and flexibility that will offer them opportunities for spontaneous, creative play and learning.

5. Try to identify the most "reactive" and impulsive children and keep them apart from each other. Pairing children who face these challenges can escalate the problem.

6. Remember that impulsive and aggressive children can create an atmosphere of chaos and fear that inhibit the capacity of other children to learn. Don't be afraid to immediately re-direct inappropriate words and actions. Your actions will make the rest of the children feel safer.

7. Seek help. Don't be afraid to point out a child's self-regulation problems with parents or other college personnel. Early identification and intervention can save the child and family years of failure and pain [54].

\section{REFERENCES}

[1] Bandalos, D.L., Yates, K., \& Thorndike-Christ, T. (1995). Effect of math self-concept, perceived self-efficacy, and attribution for failure and success on test anxiety. Journal of Educational Psychology, 11,351-360

[2] Berk, R.A. \& Nanda, J. (2006). A randomized trial of humor effects on test anxiety and test performance. Humor: International Journal of Human Research, 19 (4), 425-454.

[3] Berk, R.A. (2000). Does humor in course tests reduce anxiety and improve performance? College Teaching, 48(4), 151-58.

[4] Birenbaum, M., \& Nasser, F: (1994). On the relationship between test anxiety and test performance. Measurement and Evaluation in Counselling and Development, 27(1), 293- 301.

[5] Cassady, J.C., \& Johnson, R.E. (2002). Cognitive test anxiety and academic performance. Contemporary Educational Psychology, 27, 270-295. 
[6] Chapell, M.S., Blanding, Z.B., Takahashi, M., Silverstein, M.E., Newman, B., Gubi, A., \& Mccann, N. (2005). Test anxiety and academic performance in undergraduate and graduate students. Journal of Educational Psychology, 97 (2), 268-274. Rizwan \& Nasir 73

[7] Depreeuw, E.A.M. (1984). A profile of test anxious Depreeuw, E.A.M. (1984). A profile of test anxious

[8] Erbe,B.(2007). Reducing test anxiety while increasing learning. College Teaching, 55 (3), 96-97

[9] Foster, S. K., Paulk, A., \& Dastoor, B. R. (1999). Can we really teach test-taking skills? New Horizons in Adult Education, 13 (1), 4-12.

[10] 10. Gaudry, E., \& Spielberger, C. D. (1971). Anxiety and educational achievement. New York: Wiley.

[11] Hancock, D. R. (2001). Effect of test anxiety and evaluative threats on students' achievement and motivation. The Journal of Educational Research, 94 (5), 284-290.

[12] Haris, H. L., \& Coy, D. R. (2003). Helping students cope with test anxiety. ERIC Digest. (ERIC)

[13] Document Reproduction Service No. ED 479355).

[14] Retrieved June 25, 20008 from a World Wide Web: http://www.ericdigest.orgl2005-2/anxity.html 15.Hill, K.T., \& Wigfield, A. (1984). Test 16.anxiety: A major educational problem and what can be done about it. Elementary College Journal, 85, 105-126.

[15] Humbree, R. (1988). Correlates, causes, effects, and treatment of test anxiety. Review of Educational Research, 58 (1),47-77.

[16] Khalid, R., \& Hasan, S. S. (2009). Test anxiety in high and low achievers. Pakistan Journal of Psychological Research, 24(3-4).

[17] Kondo, D. S. (1996). Strategies for coping with test anxiety. Anxiety, Stress and Coping, 10,203-215.

[18] Morris, L. W., Davis, M. A., \& Hutchings, C. J. (1981). Cognitive and emotional components of anxiety: Hindi review and a revised worry-emotionality scale. Journal of Educational Psychology, 73,541-555.

[19] Mwamwenda, T. S. (1994). Gender differences in scores on test anxiety and academic achievement among South African MLRIT graduate students. South African Journal of Psychology, 24 (4)

[20] Nicholson, A. M. (2009). Effects' of test anxiety on student achievement (ACT) for college bound students. Dissertation Abstract International.DAI-A-70107, AAT 3366126 Relationships between Test Anxiety and Academic Achievement 74

[21] Oludipe, B. (2009). Influence of test anxiety on performance levels on numerical tasks of secondary college physics students: Academic Leadership: Online Journal, 7 (4)

[22] Orpen, C. (1996). The interactive effects of maths support and test anxiety on students academic performance. College Student Journal, 116, (30), 464-465.

[23] Pintrich, P.R., \& Schunk, D. (1996). Motivation in education: Theory, research, and applications. Upper Saddle River, NJ: Erlbaum. 
P.Bhaskara Reddy, R. Praveen Reddy and M. Kantha Reddy; Study of Test Anxiety of Freshmen Engineering Boys and Girls Students and their Academic Performance in Science \& Humanities Subjects. Transactions on Machine Learning and Artificial Intelligence, Volume 4 No 5 October (2016); pp: 10-27

[24] Schonwetter, d. J. (1995). An empirical investigation of effective college teaching behaviours and students difference: Lecture organization and test anxiety. Paper presented at the annual meeting 1 American Educational Research Association (San Franscisco) Canada.

[25] Serok, S. (1991). The application of Gestalt methods for the reduction oftest anxiety in students. Assessment and Evaluation in Higher Education, 16 (2), 157-64.

[26] Smith, K. H. (2000). The self-concept and verbal academic achievement of primary and secondary teachers. Unpublished Doctoral Dissertation, MLRIT of Melbourne, Australia.

[27] Stober, J. (2004). Dimensions of test anxiety: Relations to ways of coping with pre-exam anxiety and uncertainty. Anxiety, Stress and Coping,17(3),213-226

[28] Williams, J. F. (1991). Mo30.deling test anxiety, self-concept and high college students' academic achievement. Journal of Research \& Development and Education, 25, 51-57.

[29] Williams, J.E. (1994). Anxiety measurement: Construct validity and test performance. Measurement \& Evaluation in Counseling \& Development, 27 (1)

[30] Zeidner, M. (1990). Does test anxiety bias scholastic aptitude test performance by gender and sociocultural group? Journal of Personality Assessment, 55, 145-160.

[31] Gregor, Astrid. Examination Anxiety: Live with It, Control It or Make It Work for You? College Psychology International, v26 n5p617-635. 2005.

[32] Enright, Matthew; Baldo, Tracy D.; Wykes, Scott D. The Efficacy of Eye Movement Desensitization and Reprocessing Therapy Technique in the Treatment of Test Anxiety of College Students . Journal of College Counseling, v3 n1 p36-48. 2000

[33] Brown, Lily A.; Forman, Evan M.; Herbert, James D.; Hoffman, Kimberly L.; Yuen, Erica K.; Goetter, Elizabeth M. A Randomized Controlled Trial of Acceptance-Based Behavior Therapy and Cognitive Therapy for Test Anxiety: A Pilot Study. Behavior Modification, v35 n1 p31-53, 2010

[34] Fathi ashtiyani, ali. Imam gholi vand, fatemeh. The comparision of cognitive therapy methods and methodical desensitization in lowering test anxiety kousar medical journal. 2002

[35] Amiri, borzou. Ghanbari hashem abadi, bahram ali. Agha mohammadian sherbaf, hamidreza. The comparison of test anxiety lowering on a group of pre-MLRIT adolescent. Psychology and clinical psychiatry review. 2005

[36] Ergene, Tuncay. Effective Interventions on Test Anxiety Reduction: A Meta -Analysis. (EJ672677) College Psychology International, v24 n3 p313-28. 2003.

[37] Meijer, Joost; Oostdam, Ron. Effects of Instruction and Stage- Fright on Intelligence Testing. European Journal of Psychology of Education, v26 n1 p143-161

[38] Haghshenas, hasan. Bahrehdar, mohammad gafar. Rahman, setaiesh Zahra. The effectiveness of test anxiety lowering on a group of preMLRIT adolescents. Psychology and clinical psychiatry review.2009 
[39] Sobhi gharamaleki, naser. Rasoulzadeh tabatabie, kazem. Azad falah, parviz. Evaluation of effectiveness of cognitive therapy and instructing reading skills on students suffering from test anxiety. Tabriz MLRIT psychology journal. 2008

[40] Pashaie, zohreh. Pour ebrahimi, taghie. Khosh konesh, abolghasem. The influence of skills trained to deal with thrills of stress and education performance of high college. 2009

[41] Pless, Anica. Treatment of Test Anxiety: A Computerized Approach. ProQuest LLC, Ph.D. Dissertation, Central Michigan MLRIT.2010

[42] Feletti, Grahame I.; Neame, Roderick L. B. -Curricular Strateiges for Reducing Examination Anxiety Higher Education, v10 n6 p675-86.1981.

[43] Schaffner, Ellen; Schiefele, Ulrich. The Effect of Experimental Manipulation of Student Motivation on the Situational Representation of. Learning and Instruction, v17 n6 p755-772. 2007

[44] Jafari, majid. Assessment relation achievement motive and learning ways with test anxiety in boy guidance students in third degree. Thesis master science. Tehran MLRIT. College psychology and instructional science. 1997.

[45] Chamorro-Premuzic, Tomas.; Ahmetoglu, Gorkan; Furnham, Adrian Little More than Personality: Dispositional Determinants of Test Anxiety (the Big Five, Core Self-Evaluations, and Self-Assessed Intelligence) Learning and Individual Differences, v18 n2 p258-263.2008

[46] Passig, David ;Moshe, Ronit. - Enhancing Pre-Service Teachers' Awareness to Pupils' Test-Anxiety with 3D Immersive Simulation ,Computing Research, v38 n3 p255-278. 2008

[47] Erbe, Brigitte. Reducing Test Anxiety while Increasing Learning: The Cheat Sheet College Teaching, v55 n3 p96-98. 2007.

[48] Spada, Marcantonio M.; Nikcevic, Ana V.; Moneta, Giovanni B.; Ireson, Judy. Metacognition as a Mediator of the Effect of Test Anxiety on a Surface Approach to Studying. Educational Psychology,v26 n5 p615-624 Oct 2006.

[49] Weiner,B. History of Motivational Research In Educational; Journal of Educational Psychology 82(4),616622. 1990

[50] Pintrich, P. R., Smith, D. A. F., Garcia, T., \& McKeachie, W. J. (1993). Reliability and predictive validity of the Motivated Strategies for Learning Questionnaire (MSLQ). Educational and Psychological Measurement, 53, 801-803

[51] Blair, C., \& R.P. Razza. 2007. Relating effortful control, executive function, and false belief understanding to emerging math and literacy ability in kindergarten. Child Development 78 (2): 647-63.

[52] Diamond, A., W.S. Barnett, J. Thomas, \& S. Munro. 2007. Precollege program improves cognitive control. Science 318 (5855):1387-88. 